\title{
Validación de una prueba serológica para detectar la infección por Helicobacter pylori en Costa Rica
}

\author{
Ericka Méndez-Chacón ${ }^{1,2 *}$, Vanessa Ramírez ${ }^{1}$, Wendy Malespín-Bendaña ${ }^{1}$, \\ Guillermo Pérez-Pérez ${ }^{3} \&$ Clas Une ${ }^{1 *}$ \\ 1. Instituto de Investigaciones en Salud, Universidad de Costa Rica; ericka.mendez@ucr.ac.cr, \\ vanessa.ramirez@ucr.ac.cr,wendy.malespin@ucr.ac.cr, allan.une@ucr.ac.cr \\ 2. Centro Centroamericano de Población y Escuela de Estadística, Universidad de Costa Rica, San José, Costa Rica. \\ 3. Escuela de Medicina, Universidad de Nueva York, Nueva York, Estados Unidos de América; \\ gperezperez05@gmail.com \\ * Correspondencia
}

Recibido 17-X-2019. Corregido 13-I-2020. Aceptado 16-III-2020.

\begin{abstract}
Validation of a serological test for Helicobacter pylori infection in Costa Rica. Introduction: Helicobacter pylori is a Gram-negative bacterium capable to survive and multiply in the gastric mucosa. It is the most prominent factor in the development of chronic atrophic gastritis, peptic ulcer, adenocarcinoma and MALT lymphoma. It is estimated that half the world population is infected. The economic cost and impact on the quality of life caused by $H$. pylori are important. There are several methods to detect the bacteria, but some are invasive, expensive, or both. Objective: We compare an inexpensive serological test based on ELISA for the detection of IgG, using the urea breath test (PYtest) as the reference method. Methods: The area under the ROC curve, sensitivity, specificity and predictive values were calculated. A subset of 45 samples was used for validation of the ELISA test, while the assay was evaluated with 185 additional samples. Results: The cut-off point to discriminate between positive and negative infection status by $H$. pylori was 0.75 , using the optical density ratio of each serum and a positive control. With a higher value of the ratio, the probability of being infected increased. Using this criterion, the test showed a sensitivity of $91.4 \%$ and specificity of $93.7 \%$. All diagnostic values improved when a gray zone was considered. Conclusion: The serological test developed here is equivalent to the urea breath test. However, the serological test is more accessible to the general population because of its lower cost. This serological test could be used in large-scale clinical research.
\end{abstract}

Key words: Helicobacter pylori; gastritis; gastric cancer; ELISA; IgG; serology; sensitivity; specificity.

Méndez-Chacón, E., Ramírez, V., Malespín-Bendaña, W., Pérez-Pérez, G., \& Une, C. (2020).

Validación de una prueba serológica para detectar la infección por Helicobacter pylori en Costa Rica. Revista de Biología Tropical, 68(2), 551-562.

Helicobacter pylori es una bacteria Gram negativa capaz de sobrevivir y multiplicarse en la mucosa gástrica (Atherton \& Blaser, 2009). Su presencia produce inflamación crónica que puede persistir toda la vida. La infección por H. pylori es reconocida como el factor más importante en el desarrollo de diversas afecciones gástricas (gastritis crónica atrófica, úlcera péptica, linfoma MALT y adenocarcinoma).
Está clasificada como un agente carcinógeno tipo I (International Agency for Research on Cancer [IARC], 2012). En la mayoría de los casos la infección permanece asintomática. Una fracción de las personas infectadas desarrollan cáncer gástrico $(\mathrm{CG})$ (El-Omar, $\mathrm{Ng}, \&$ Hold, 2008). El proceso de carcinogénesis se caracteriza por inflamación severa y atrofia del cuerpo del estómago, que puede ser seguido 
por metaplasia, displasia y finalmente adenocarcinoma (Correa \& Piazuelo, 2012).

La bacteria $H$. pylori también participa en el desarrollo de úlcera duodenal, que se caracteriza por gastritis antral y alta secreción de ácido. De los individuos infectados por $H$. pylori en occidente, se estima que hasta un 15 $\%$ desarrollaría úlcera duodenal, mientras que cerca de un $3 \%$ un adenocarcinoma (Peek \& Blaser, 2002; El-Omar et al., 2008). Por estas razones, el impacto en la calidad de vida y el costo económico causados por $H$. pylori es importante.

Se estima que, en el mundo, la mitad de la población ha sido infectada por $H$. pylori durante la niñez (Suerbaum \& Michetti, 2002; IARC, 2012). Las tasas de prevalencia varían de acuerdo con el grado de desarrollo del país (IARC, 2012), la edad y la zona geográfica (Ford \& Axon, 2010). No existen diferencias por sexo, sin embargo, el nivel socio económico y una mala condición de la vivienda están asociados con la infección (Porras et al., 2013).

En Costa Rica hay indicios de altas tasas de prevalencia de la infección por esta bacteria, en reportes de los últimos 30 años. Según Sierra et al. (1992) la prevalencia de H. pylori en niños y adolescentes de zonas de bajo y alto riesgo de $\mathrm{CG}$, eran de 74 y $65 \%$ respectivamente. En pacientes dispépticos, se ha reportado una prevalencia entre 54 y $93 \%$ en adultos (Blanco-Delgado et al., 2001; Alpízar-Alpízar, Pérez-Pérez, Une, Cuenca, \& Sierra, 2005; Con et al., 2007) y cerca de $32 \%$ en niños (Rivera, Carranza, \& Hernández-Chavarría, 2003). En la provincia de Guanacaste, Costa Rica, en personas mayores de 20 años, se encontró que 78 de cada 100 estaban infectadas por H. pylori (Porras et al., 2013).

A pesar de que a nivel mundial menos de un $3 \%$ de los individuos infectados por H. pylori desarrollan neoplasias (de Martel et al., 2012); la incidencia mundial de infección por esta bacteria es tan alta que la cantidad de personas en números absolutos que pueden desarrollan neoplasias es importante. En 2012 se presentaron 951600 casos nuevos de CG a nivel mundial (de Martel et al., 2012) y 770000 casos fueron atribuidos a la bacteria $H$. pylori (de Martel et al., 2012; Plummer, Franceschi, Vignat, Forman, \& de Martel, 2015; Plummer et al., 2016).

Existen varios métodos para diagnosticar la infección por H. pylori. Entre las técnicas invasivas se puede mencionar el examen histológico, el cultivo, y la prueba de ureasa rápida, estas requieren de una endoscopía gástrica para la toma de biopsias (Tonkic, Tonkic, Lehours, \& Mégraud, 2012; Pilotto \& Franceschi, 2014). Las pruebas por endoscopía tienen sensibilidades altas; pero el procedimiento es caro e incómodo para el paciente, y conlleva el riesgo de hemorragia y perforación. La precisión y exactitud del diagnóstico están relacionadas con el sitio, el número, el tamaño de las biopsias tomadas y la experiencia del endoscopista (Ricci, Holton, \& Vaira, 2007).

Las técnicas no invasivas como las pruebas de urea en aliento, pruebas de tipo serológico y detección de antígeno en orina o heces (Ricci et al., 2007; Tonkic et al., 2012; Pilotto \& Franceschi, 2014) son relativamente más económicas que las técnicas invasivas (Pattison, Combs, \& Marshall, 1997; Mégraud, Bessede, \& Lehours, 2014) y menos agresivas para las personas; por lo que son más accesibles y podrían aplicarse a la población general en el manejo de atención primaria (Ricci et al., 2007). En Costa Rica, varios laboratorios realizan el diagnóstico de la infección por $H$. pylori en suero o en heces (con precios que fluctúan entre los \$25 y \$50) y la prueba de urea en aliento (cuesta cerca de \$100). Realizar pruebas de detección de $H$. pylori utilizando el método que se propone en este artículo, reduciría substancialmente el costo.

Este estudio evalúa una prueba serológica para la detección de $H$. pylori desarrollada en el Programa de Epidemiología del Cáncer del Instituto de Investigaciones en Salud (INISA) de la Universidad de Costa Rica (UCR). La prueba está basada en antígenos derivados de cinco cepas aislados de pacientes costarricenses. Se puede utilizar en el diagnóstico de la infección por $H$. pylori; además de implementarse como prueba en estudios epidemiológicos para 
investigar la prevalencia. Su costo estimado es menos de $\$ 1.00$ por muestra por concepto de materiales (no incluye mano de obra, infraestructura o preparación de antígeno). Requiere de una muestra de sangre obtenida por venopunción, por lo que resulta aceptable para la persona a la cual se le realiza. Para validarla, se comparó con la prueba de urea en aliento, como método de referencia, de la cual se conoce que es una prueba muy exacta y con un alto desempeño en ensayos clínicos (Chey, 2000).

\section{MATERIALES Y MÉTODOS}

Participantes: Se estudiaron 240 personas funcionarias de la UCR, las cuales firmaron un consentimiento informado. Las muestras se recolectaron en la UCR durante el 2008 y 2009. El proyecto contó con la aprobación del Comité Ético Científico de la UCR.

Criterios de inclusión y exclusión: Se incluyeron en el estudio funcionarios de la UCR mayores de 18 años. Se excluyeron las personas que tomaron medicamentos para erradicar la bacteria Helicobacter pylori en algún momento de su vida; tomaron antibióticos o Metronidazol en los 3 meses anteriores a la prueba; y recibieron tratamiento (inhibidores de bomba de protones y compuestos de bismuto) contra la acidez, la gastritis o úlceras en las dos semanas anteriores a la prueba.

Toma de muestra: Se hizo una flebotomía de la vena mediana cefálica o mediana basílica del antebrazo, después de $6 \mathrm{~h}$ de ayuno; también se realizó una prueba de urea en aliento. El mismo día de la toma se separó el suero y se almacenó a $-70{ }^{\circ} \mathrm{C}$, también se enviaron las bolsas de aliento al laboratorio Sáenz Renauld para la determinación de $H$. pylori (técnica de urea en aliento).

Estándar de oro - Prueba de urea en aliento: Para la prueba de urea en aliento se usó el kit Pytest (Ballard Medical Products, USA). Cada participante ingirió una cápsula de urea marcada con carbono 14 (C-14), con
$20 \mathrm{ml}$ de agua. A los tres minutos de ingerida se le proporcionaron otros $20 \mathrm{ml}$ de agua. Diez minutos después, el participante sopló un globo especial a través de una pajilla, hasta llenarlo. El globo fue cerrado y enviado al laboratorio para su análisis.

El resultado de la prueba en aliento se determinó a través de la liberación de $\mathrm{CO} 2$ marcado con el isótopo, lo cual se reporta como desintegraciones por minuto (DPM). Si el conteo de DPM fue superior a 200 DPM, la prueba se consideró positiva para $H$. pylori, si fue inferior a 50 DPM se consideró negativa. Valores de DPM que se encuentren entre 5 y 200 , se consideraron como indeterminados.

\section{ELISA}

La determinación de anticuerpos ( $\mathrm{IgG}$ ) contra $H$. pylori se realizó mediante una prueba de ELISA (Enzyme Linked Immunosorbent Assay) elaborada en el INISA. Esta prueba está basada en un método desarrollado por PérezPérez et al. (1988). El antígeno fue preparado a partir de cinco cepas de $H$. pylori, aisladas de pacientes dispépticos del Hospital Calderón Guardia en San José, Costa Rica. Después de cultivar las cepas, una suspensión de cada una fue sonicada 7 veces por 30 segundos. Después de la centrifugación (2900 rpm, $20 \mathrm{~min}$ ) se determinó la concentración de proteínas en el sobrenadante. Se ajustó la concentración a $1 \mathrm{mg} / \mathrm{ml}$ y se mezclaron las preparaciones de las 5 cepas a cantidades iguales. Se almacenaron alícuotas de $1 \mathrm{ml} \mathrm{a}-70{ }^{\circ} \mathrm{C}$.

El método utiliza controles positivos para corregir los resultados de cada placa y un control negativo interno para excluir señales inespecíficas. Para seleccionar los controles se realizó la prueba con suero de 40 voluntarios de la Facultad de Microbiología de la UCR diferentes a los participantes del estudio. Entre ellos, se seleccionaron los cuatro sueros que mostraron la absorbancia más alta como controles positivos. Para contar con un suministro suficiente se unieron esos sueros dos y dos. Como control negativo se escogió un suero con absorbancia baja. 
Se utilizaron placas de 96 pozos de la marca Immulon 2B (ThermoScientific, New York). Para cubrir la placa se diluyó el antígeno a una concentración de $10 \mu \mathrm{g} / \mathrm{ml}$ en buffer de carbonato $0.05 \mathrm{~mol} / \mathrm{L} \mathrm{pH} 9.6$ y se colocaron $100 \mu \mathrm{l}$ de la solución para una cantidad final de $1 \mu \mathrm{g}$ por pozo. La placa se incubó a temperatura ambiente toda la noche. Se colocó en $250 \mu \mathrm{l}$ de gelatina al $1 \%$ en PBS y se incubó por tres horas a $37{ }^{\circ} \mathrm{C}$, con el fin de bloquear cualquier adherencia inespecífica.

Las placas fueron lavadas tres veces entre cada paso en PBS con timerosal al $0.01 \%$ y polisorbato 20 (Tween 20) al $0.05 \%$. Las muestras utilizadas y los controles negativos fueron diluidas 1:800 en PBS con gelatina al $1 \%$ y gama-globulina bovina al $0.5 \%$ (Sigma USA). Los controles positivos fueron diluidos 1:7500. Se agregaron $100 \mu \mathrm{l}$ de la dilución a cada uno de los pozos y se incubaron a $37^{\circ} \mathrm{C}$ durante una hora.

Todas las muestras y controles se analizaron por duplicado. En cada placa se dejó dos pozos con solo PBS (identificados como blanco) para medir la absorbancia inespecífica. De todos los valores de las muestras y controles se restó el valor del blanco. En la parte superior se colocó un control negativo y dos controles positivos. Los controles positivos y negativos se colocaron de la misma forma en la parte inferior de la placa para garantizar que las placas se comportaran de forma uniforme (Fig. 1).

Después del lavado, se agregaron $100 \mu \mathrm{l}$ de suero anti-IgG humano conjugado con fosfatasa alcalina (Biosource International, USA) diluido 1:2000 en PBSTT + Gammaglobulina bovina $0.1 \%$ + Albumina Bovina $1.0 \%$. Las placas fueron incubadas durante una hora a $37{ }^{\circ} \mathrm{C}$, posteriormente fueron lavadas cinco veces. Luego se agregaron $100 \mu \mathrm{l}$ de sustrato (Fast p-Nitrophenyl Phosphate Tablet Sets, Sigma, USA) y fueron incubadas a $37^{\circ} \mathrm{C}$ hasta que la absorbancia neta a $405 \mathrm{~nm}$ excediera la densidad óptica (DO) en 0.4 para los controles positivos. La absorbancia fue determinada en un espectrofotómetro Multiscan (ThermoLabsystems, Finlandia).

Los resultados de la serología se expresan como la razón de densidades:

$$
\frac{\text { DO neta de la muestra }}{\text { DO neta de los controles positivos }}
$$

\section{Análisis estadístico}

La prueba de ELISA se realizó por duplicado en cada placa y se repitió, hasta ocho veces por persona, dependiendo de la cantidad de suero disponible. La información se analizó en dos etapas; en la primera etapa se valoró la calidad de los datos que se generaron de cada placa y se obtuvo la razón de densidades final. En la segunda etapa se validó la prueba serológica con respecto a la prueba de aliento. A continuación, se detalla el procedimiento a seguir.

\section{Transformación y evaluación de la calidad de los datos}

1. Transformación de datos y cálculo de promedios.

\begin{tabular}{|c|c|c|c|c|c|c|c|c|c|c|c|c|}
\hline \multirow{2}{*}{ Fila } & \multicolumn{12}{|c|}{ Columna } \\
\hline & 1 & 2 & 3 & 4 & 5 & 6 & 7 & 8 & 9 & 10 & 11 & 12 \\
\hline $\mathbf{A}$ & W & W & - & - & + & + & + & + & p1 & p1 & p2 & p2 \\
\hline B & p3 & p3 & $\mathrm{p} 4$ & $\mathrm{p} 4$ & $\mathrm{p} 5$ & p5 & p6 & p6 & $\mathrm{p} 7$ & p7 & p8 & $\mathrm{p} 8$ \\
\hline C & p9 & p9 & p10 & p10 & pl1 & p11 & p12 & p12 & p13 & $\mathrm{p} 13$ & p14 & p14 \\
\hline D & p15 & $\mathrm{p} 15$ & p16 & p16 & p17 & $\mathrm{p} 17$ & p18 & p18 & p19 & p19 & p20 & p20 \\
\hline $\mathbf{E}$ & p21 & $\mathrm{p} 21$ & p22 & $\mathrm{p} 22$ & $\mathrm{p} 23$ & $\mathrm{p} 23$ & $\mathrm{p} 24$ & p24 & $\mathrm{p} 25$ & p25 & p26 & p26 \\
\hline $\mathbf{F}$ & $\mathrm{p} 27$ & $\mathrm{p} 27$ & $\mathrm{p} 28$ & $\mathrm{p} 28$ & p29 & p29 & p30 & p30 & p31 & p31 & p32 & p32 \\
\hline $\mathbf{G}$ & p33 & p33 & p34 & p34 & p35 & p35 & p36 & p36 & p37 & p37 & p38 & p38 \\
\hline $\mathbf{H}$ & p39 & p39 & $\mathrm{p} 40$ & $\mathrm{p} 40$ & $\mathrm{p} 41$ & p41 & - & - & + & + & + & + \\
\hline
\end{tabular}

Fig. 1. Ejemplo de la distribución de los sueros en las placas. $\mathrm{W}=$ blanco, $-=$ control negativo, $+=$ control positivo, $p_{i}=$ muestra de la persona $i$.

Fig. 1. Example of the distribution of sera in the plates. W: blank, -: negative control, +: positive control, $p_{i}$ : serum sample of person i. 
Los resultados de la DO provienen en el mismo formato de una placa (Fig. 1). Las dos primeras celdas, indicadas con la letra $\mathrm{W}$, no contienen ningún anticuerpo y corresponden al blanco, estos reflejan el valor correspondiente al material de la placa, los que se usaron posteriormente para ajustar los cálculos aislando este efecto. Las celdas A3 y A4 y las celdas H7 y H8 contienen los valores control de sueros negativos. Las celdas A5 a la A8 y H9 a la H12, corresponden a la mezcla de sueros positivos para H. pylori. El resto de las celdas indicadas con la letra "p", corresponden a los sueros de las personas participantes. Cada suero se corrió en duplicado para cada persona, por ejemplo, las columnas A9 y A10 corresponden al suero de la persona $1(\mathrm{p} 1)$.

Se calcularon los promedios de los valores de las celdas: blancos, positivos, negativos y de los pares de muestras para cada persona por placa. Los controles positivos y negativos se colocaron de la misma forma en la parte inferior de la placa.

2. Revisión de consistencia de los controles entre placas: promedios de los blancos, negativos y positivos.

Se revisó que los valores promedio de las celdas llamadas "blanco", "negativo" y "positivo" entre placas fueran muy parecidos, esto con el fin de identificar posibles problemas durante la ejecución del experimento entre las placas. Se utilizaron técnicas gráficas de control de calidad y análisis de varianza, para asegurar la estabilidad y calidad de los datos durante la ejecución de las pruebas.

3. Aislar el efecto del color del material de la placa.

El valor promedio de DO obtenido del espacio "blanco" en cada placa se sustrajo a todos los demás valores resultantes de la misma placa, incluidos los controles negativos y positivos. Por ejemplo, al promedio de los pares de la persona 1 (denotada por p1) en la placa 1, se le resta el promedio de blancos en la misma placa. El proceso se repite para todas las personas en todas las placas. Algebraicamente:

$$
v p 1 s b=p p 1-p b
$$

$b$ es el valor medio de las celdas "blanco" en la placa 1 .

4. Calcular la razón de DO para cada persona por placa. En el caso de la persona 1, en la placa 1, se calcula de la siguiente manera:

$$
D O=\frac{v p 1 s b}{(\text { promedio de positivos }-p b)}
$$

5. Se obtiene el promedio de la razón de densidad por persona en todas las placas, con el fin de obtener un registro único. En el caso de la persona 1, se calcularía así:

Do final persona $1=\frac{\text { DO placa } 1+D O \text { placa } 2+\cdots+D O \text { placa } 8}{8}$

\section{Validación de la prueba diagnóstica}

De las 240 muestras se excluyeron de la validación 10 debido a que dieron valores indeterminados en la prueba de urea en aliento. La muestra de 230 resultados válidos se separó en dos partes, con la finalidad de contar con un conjunto de datos para determinar los puntos de corte $(\mathrm{N}=45)$ y luego, validarlos y evaluarlos en la submuestra más grande $(\mathrm{N}=185)$ y así evitar sesgos positivos de la prueba.

La muestra de 45 sueros se seleccionó al azar manteniendo la estructura por grupo decenal de edad y sexo. En la tabla 1 se muestra la distribución porcentual de cada conjunto de datos según grupo de edad, sexo y condición por prueba de urea en aliento. La distribución según las características mencionadas es muy similar en ambos conjuntos de datos, lo que evita sesgos en la validación de la prueba. 
TABLA 1

Distribución porcentual de los participantes, en cada muestra, según clasificación en la prueba de aliento y grupo de edad

TABLE 1

Percentual distribution of participants by sub-sample, according to breath test classification and age group

\begin{tabular}{|c|c|c|c|c|c|c|c|c|}
\hline \multirow{3}{*}{ Grupo de edad } & \multicolumn{4}{|c|}{ Submuestra $(\mathrm{N}=45) /$ condición por urea } & \multicolumn{4}{|c|}{ Submuestra $(\mathrm{N}=185) /$ condición por urea } \\
\hline & \multicolumn{2}{|c|}{ Positivos $(55.6 \%)$} & \multicolumn{2}{|c|}{ Negativos (44.4\%) } & \multicolumn{2}{|c|}{ Positivos $(56.8 \%)$} & \multicolumn{2}{|c|}{ Negativos (43.3\%) } \\
\hline & $\begin{array}{l}\text { Hombres } \\
(\mathrm{N}=10)\end{array}$ & $\begin{array}{l}\text { Mujeres } \\
(\mathrm{N}=15)\end{array}$ & $\begin{array}{c}\text { Hombres } \\
(\mathrm{N}=7)\end{array}$ & $\begin{array}{l}\text { Mujeres } \\
(\mathrm{N}=13)\end{array}$ & $\begin{array}{l}\text { Hombres } \\
(\mathrm{N}=38)\end{array}$ & $\begin{array}{l}\text { Mujeres } \\
(\mathrm{N}=67)\end{array}$ & $\begin{array}{l}\text { Hombres } \\
(\mathrm{N}=30)\end{array}$ & $\begin{array}{l}\text { Mujeres } \\
(\mathrm{N}=50)\end{array}$ \\
\hline $18-29$ & 10.0 & 26.7 & 42.9 & 38.5 & 7.9 & 29.9 & 40.0 & 34.0 \\
\hline $30-39$ & 20.0 & 13.3 & 28.6 & 23.1 & 18.4 & 14.9 & 23.3 & 24.0 \\
\hline $40-49$ & 50.0 & 46.7 & 14.3 & 30.8 & 55.3 & 41.8 & 20.0 & 30.0 \\
\hline $50-64$ & 20.0 & 13.3 & 14.3 & 7.7 & 18.4 & 13.4 & 16.7 & 12.0 \\
\hline Total & 100.0 & 100.0 & 100.0 & 100.0 & 100.0 & 100.0 & 100.0 & 100.0 \\
\hline Edad promedio & \multicolumn{4}{|c|}{$38.1 \pm 9.8$} & \multicolumn{4}{|c|}{$38.4 \pm 10.7$} \\
\hline$\%$ hombres & \multicolumn{4}{|c|}{37.8} & \multicolumn{4}{|c|}{36.8} \\
\hline
\end{tabular}

1. Determinación del punto de corte.

La muestra de tamaño 45 se utilizó para calcular el punto de corte de la razón de la DO para determinar el estado de las personas como positivo o negativo según la prueba en sangre. Se realizó un análisis de regresión logística y curvas ROC (Receiver Operating Characteristic). Se obtuvieron los valores de sensibilidad, especificidad y valores predictivos en relación con la prueba de aliento. Además, se definieron varias zonas grises (zonas de resultados indeterminados). Para identificar las zonas grises de clasificación y obtener los límites, se definieron varios escenarios, los cuales consisten en sumar y restar al valor de corte un $5,10,15$, 20 y $25 \%$.
2. Validación de la prueba.

En el resto de la muestra $(\mathrm{N}=185)$, se validó la prueba usando el punto de corte encontrado con la muestra de 45 . Se calcularon los valores diagnósticos para el punto de corte sin zona gris y tomando en cuenta las diferentes zonas grises definidas en el punto anterior.

\section{RESULTADOS}

Datos generales de los participantes: De los 230 resultados válidos (Tabla 2), 145 eran mujeres (63\%) y 85 hombres (37\%). La edad promedio de todos los participantes fue de 38.4 años con una desviación estándar de 10.5. Según la prueba de aliento, 130 personas (57\%)

TABLA 2

Valores promedio del suero según clasificación en la prueba de aliento $(\mathrm{N}=240)$

TABLE 2

Average serum values according to breath test classification $(\mathrm{N}=240)$

\begin{tabular}{|c|c|c|c|c|}
\hline \multirow{2}{*}{$\begin{array}{l}\text { Clasificación según } \\
\text { prueba de aliento }\end{array}$} & \multicolumn{3}{|c|}{ Valor medio de la razón de densidad óptica } & \multirow{2}{*}{ Cantidad de personas } \\
\hline & Promedio & Desviación estándar & IC $95 \%$ & \\
\hline Negativo & 0.32 & 0.26 & $0.27-0.37$ & 100 \\
\hline Positivo & 1.49 & 0.47 & $1.41-1.57$ & 130 \\
\hline Indeterminado* & 0.69 & 0.81 & $0.11-1.27$ & 10 \\
\hline Total & 0.97 & 0.71 & & 240 \\
\hline
\end{tabular}

* Se eliminaron del análisis.

Diferencias promedio entre positivos y negativos son estadísticamente significativas $(\mathrm{P}<0.001)$.

* $\quad$ Not included in the analysis.

Average differences between positives and negatives are statistically significant $(\mathrm{P}<0.001)$. 


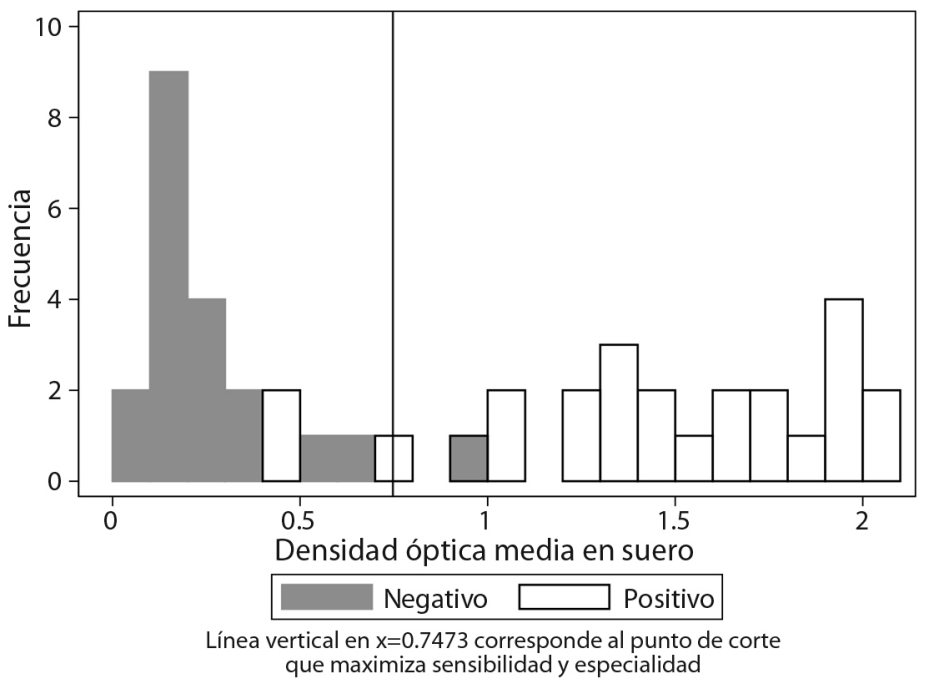

Fig. 2. Distribución de los valores de la razón de densidad óptica, según condición en prueba de aliento $(\mathrm{N}=45)$.

Fig. 2. Distribution of optical density ratio values according to breath test condition $(N=45)$.

se diagnosticaron positivas y $100(43 \%)$ negativas para la infección por Helicobacter pylori.

\section{Determinación del punto de corte} $(\mathbf{N}=\mathbf{4 5})$ : Las personas con resultados negativos muestran una distribución de los valores de DO mucho más bajos que aquellos con resultados positivos, mostrándose claramente dos conjuntos (Fig. 2).

En la tabla 3 se muestran los valores medios de la razón de la DO según condición en la prueba de aliento. Las diferencias entre positivos y negativos son estadísticamente significativas $(\mathrm{P}<0.001)$, en ambas submuestras.
Por el contrario, las diferencias promedio de la razón de la DO entre datos de las submuestras no son estadísticamente significativos $(\mathrm{P}=$ $0.57)$, lo que corrobora que ambas submuestras son comparables.

El uso de la prueba de aliento como estándar de oro para clasificar a las personas como positivas o negativas por infección de $H$. pylori, nos permitió confirmar que la prueba en suero tiene una alta sensibilidad; la capacidad de la prueba de detectar a los verdaderamente positivos para la infección por $H$ pylori fue del $92 \%$. Además, la capacidad de la prueba serológica para identificar a los casos negativos

TABLA 3

Valores promedio de la razón de la densidad óptica según clasificación en la prueba de aliento en las submuestras de ejecución y de validación

TABLE 3

Average optical density ratio according to the breath test classification in the execution and the validation subsamples

\begin{tabular}{|c|c|c|c|c|c|c|}
\hline \multirow{3}{*}{$\begin{array}{l}\text { Clasificación según } \\
\text { prueba de aliento }\end{array}$} & \multicolumn{6}{|c|}{ Valor medio de la razón de densidad óptica. } \\
\hline & \multicolumn{3}{|c|}{ Submuestra de ejecución $(\mathrm{N}=45)$} & \multicolumn{3}{|c|}{ Submuestra de validación $(\mathrm{N}=185)$} \\
\hline & Promedio & $\begin{array}{l}\text { Desviación } \\
\text { estándar }\end{array}$ & $\begin{array}{c}\text { Cantidad de } \\
\text { personas }\end{array}$ & Promedio & $\begin{array}{l}\text { Desviación } \\
\text { estándar }\end{array}$ & $\begin{array}{c}\text { Cantidad de } \\
\text { personas }\end{array}$ \\
\hline Negativo & 0.267 & 0.214 & 20 & 0.330 & 0.274 & 80 \\
\hline Positivo & 1.452 & 0.470 & 25 & 1.496 & 0.467 & 105 \\
\hline Total & 0.925 & 0.704 & 45 & 0.992 & 0.701 & 185 \\
\hline
\end{tabular}


TABLA 4

Valores diagnósticos de la prueba en suero para detectar Helicobacter pylori, utilizando un punto de corte de 0.7473 en la razón de densidad óptica

TABLE 4

Diagnostic values of the serum test for detecting H. pylori, using 0.7473 as optical density cut-off point ratio

\begin{tabular}{llll}
\hline Sensibilidad & 92.0 & Tasa de falsos negativos & 8.0 \\
Especificidad & 95.0 & Tasa de falsos positivos & 5.0 \\
Valor predictivo positivo & 95.8 & & \\
Valor predictivo negativo & 90.5 & & \\
\hline
\end{tabular}

Valores obtenidos con la muestra $(n=45)$. Values obtained for the $n=45$ sample.

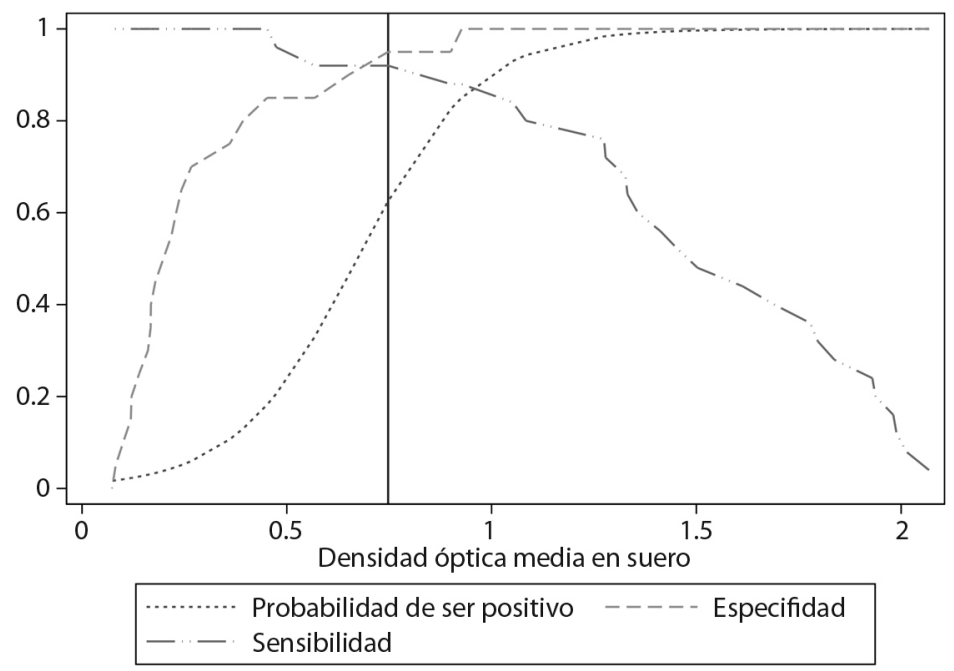

Fig. 3. Sensibilidad, especificidad y probabilidad de un resultado positivo para infección por Helicobacter pylori, según valores de la prueba en suero $(\mathrm{N}=45)$. La línea vertical indica el punto de corte $(0.7473)$.

Fig. 3. Sensitivity, specificity and probability of a positive result for $H$. pylori infection, according to serum test values (N $=45)$. The vertical line indicates the cut-off point (0.7473).

fue del $95 \%$ (especificidad). El punto de corte de la razón de DO que maximiza, tanto la sensibilidad como la especificidad, es de 0.7473 (Tabla 4, Fig. 3).

En la figura 3 se observan las curvas de sensibilidad, especificidad y también la probabilidad de tener infección por $H$. pylori según el valor de la DO. La probabilidad de ser positivo para la infección por $H$. pylori, aumenta conforme aumenta el valor de la razón de DO.

El desempeño del modelo se evaluó a través del cálculo del área bajo la curva ROC, la cual fue de 0.9860. Este resultado indica que en relación con la detección de la infección por
H. pylori, la prueba en suero es prácticamente equivalente a la prueba de aliento. Además, se establecieron los valores diagnósticos según cinco zonas grises para la prueba serológica (Tabla 5).

Validación de la prueba $(\mathbf{N}=\mathbf{1 8 5})$ : Utilizando el punto de corte de 0.7473 para la razón de la DO, se clasificó al resto de las personas de la muestra como positivos si tenían valores superiores a ese punto, y negativos si el valor de la DO era menor. En esta muestra se confirma que la prueba serológica es casi equivalente a la prueba de urea en aliento. La sensibilidad 
TABLA 5

Valores diagnósticos de la prueba en suero para detectar Helicobacter pylori, utilizando un punto de corte de 0.7473 en la razón de densidad óptica y diferentes zonas grises

TABLE 5

Diagnostic values of the serum assay for detecting H. pylori, using 0.7473 as cut-off point for the optical density ratio and different gray zones

\begin{tabular}{lcccccc} 
& & \multicolumn{5}{c}{ Zona gris para el punto de corte: 0.7473} \\
& Sin zona gris & $5 \%$ & $10 \%$ & $15 \%$ & $20 \%$ & $25 \%$ \\
Límite Inferior & $<0.7473$ & 0.7099 & 0.6726 & 0.6352 & 0.5978 & 0.5605 \\
Límite Superior & $\geq 0.7473$ & 0.7847 & 0.8220 & 0.8594 & 0.8968 & 0.9341 \\
Cantidad de personas en zona gris & 0 & 1 & 1 & 2 & 2 & 5 \\
Sensibilidad & 92.00 & 91.67 & 91.67 & 91.67 & 91.67 & 91.30 \\
Especificidad & 95.00 & 95.00 & 95.00 & 94.74 & 94.74 & 100.00 \\
Valor Predictivo Positivo & 95.83 & 95.65 & 95.65 & 95.65 & 95.65 & 100.00 \\
Valor Predictivo Negativo & 90.48 & 90.48 & 90.48 & 90.00 & 90.00 & 89.47 \\
\hline
\end{tabular}

Valores obtenidos con la muestra $(\mathrm{N}=45)$. Values obtained for the $\mathrm{N}=45$ sample.

TABLA 6

Valores diagnósticos de la prueba en suero para detectar Helicobacter pylori, utilizando un punto de corte de $0.7473(0.75)$ en la razón de densidad óptica y diferentes zonas grises

TABLE 6

Diagnostic values of the serum assay for detecting H. pylori, using $0.7473(0.75)$ as cut-off point for optical density ratio and different gray zones

\begin{tabular}{lcccccc} 
& & \multicolumn{5}{c}{ Zona gris para el punto de corte: 0.7473} \\
& Sin zona gris & $5 \%$ & $10 \%$ & $15 \%$ & $20 \%$ & $25 \%$ \\
Límite Inferior & $<0.7473$ & 0.7099 & 0.6726 & 0.6352 & 0.5978 & 0.5605 \\
Límite Superior & $\geq 0.7473$ & 0.7847 & 0.822 & 0.8594 & 0.8968 & 0.9341 \\
Cantidad de personas en zona gris & 0 & 11 & 17 & 19 & 20 & 24 \\
Sensibilidad & 91.43 & 93.88 & 93.75 & 94.74 & 94.68 & 94.62 \\
Especificidad & 93.75 & 93.42 & 95.83 & 95.77 & 95.77 & 95.59 \\
Valor Predictivo Positivo & 94.12 & 94.85 & 96.77 & 96.77 & 96.74 & 96.7 \\
Valor Predictivo Negativo & 89.29 & 92.21 & 92 & 93.15 & 93.15 & 92.86 \\
Porcentaje de clasificación correcta: & 92.43 & 88.11 & 85.95 & 85.41 & 84.86 & 82.7 \\
\hline
\end{tabular}

Valores obtenidos con la muestra de validación $(\mathrm{N}=185)$. Values obtained for the validation sample $(\mathrm{N}=185)$.

observada es de $91.4 \%$ y la especificidad es de $93.7 \%$; los valores predictivos también son altos. El porcentaje de clasificación correcto fue de $92.4 \%$.

En la tabla 6 se ofrecen los valores diagnósticos utilizando diferentes zonas grises, a partir de los valores diagnósticos observados en este grupo. Por ejemplo, si se utiliza como zona gris la establecida entre el punto de corte y una desviación del $10 \%$ de ese valor, los valores contenidos entre el intervalo 0.6726 y 0.8220 , serían los que definan la condición de positivo o negativo. En ese caso, la sensibilidad es de $93.7 \%$ y la especificidad de $95.8 \%$. El porcentaje de clasificación correcta es de $85.9 \%$.

\section{DISCUSIÓN}

Este estudio desarrolló y evaluó una prueba serológica para detectar la presencia de 
anticuerpos contra Helicobacter pylori en una población costarricense. La prueba serológica se comparó con la prueba de urea en aliento. Los resultados obtenidos (sensibilidad: 91.4\% y especificidad: $93.7 \%$ ) indican que esta prueba serológica tiene altos porcentajes de detección de infección por H. pylori. Ambos valores predictivos son muy cercanos o superiores a $90 \%$, lo que indica que es una prueba confiable para establecer si una persona está o no infectada.

El punto de corte en la razón de DO entre los sueros de las muestras y el control positivo que puede ser utilizado para discriminar mejor entre un resultado positivo y uno negativo a la infección es de 0.75 . Valores iguales o superiores, indican presencia de la infección. Cuanto mayor sea el valor de la razón, en la prueba, más probabilidad de que la persona tenga la infección.

En el 2003, se utilizó esta misma metodología por ELISA para determinar la infección por H. pylori en pacientes dispépticos del Hospital Calderón Guardia en San José. Como método de referencia, se comprobó la infección por $H$. pylori a través del uso de cultivo, ureasa rápida y tinción, en forma conjunta (Sierra et al., 2006). En esa oportunidad, la sensibilidad encontrada fue de $96 \%$ y la especificidad de $62 \%$. Los valores predictivos positivo y negativo fueron 89 y $82 \%$ respectivamente (Sierra et al., 2006). La baja especificidad y valores predictivos menores a $90 \%$, indican que podría haber detección imprecisa de casos de infección por $H$. pylori al utilizar como referentes de comparación el cultivo, la ureasa rápida y la tinción, en forma conjunta. En relación con los métodos de referencia usados en esa ocasión; la posibilidad de encontrar falsos negativos se da por varias razones; entre ellas porque el muestreo realizado por el endoscopista podría ser impreciso en algunas zonas gástricas y se podría tomar biopsias de un lugar en donde no ha crecido o ha crecido muy poco $H$. pylori, debido a que la infección no es homogénea en el estómago. Esto podría resultar en falsos positivos para la serología.
Existen kits comerciales de serología, revisados en Ho y Marshall (2000) que muestran valores diagnósticos (valores de sensibilidad y especificidad) altos y similares a la prueba de serología que se ha desarrollado. La prueba desarrollada aquí, es económica (precio por muestra $<\$ 1.00$ ), está basada en antígenos derivados de bacterias que circulan en Costa Rica y está validada en una muestra $(\mathrm{N}=185)$ que proviene de la población donde se evaluó la prueba $(\mathrm{N}=45)$; ambas muestras son estadísticamente comparables.

Esta prueba de ELISA está orientada a detectar la infección por H. pylori. Aunque dicha infección es un factor etiológico importante para el desarrollo de CG, la prueba sola no es informativa para su diagnóstico. Como es sabido, solo una pequeña fracción de los infectados por H. pylori desarrollaría CG (Peek \& Blaser, 2002), de manera que la infección no es suficiente para indicar la presencia de CG. Sin embargo, la prueba se puede implementar en conjunto con otros biomarcadores, como parte de un método económico, efectivo y eficaz de tamizaje poblacional, que sirva para ayudar a la detección temprana del CG, evitando así, exámenes de detección invasivos innecesarios. Otros biomarcadores en suero que podrían complementar un estudio para detección temprana de CG son pepsinógenos, gastrina y anticuerpos contra CagA, un factor de virulencia de H. pylori (Sierra et al., 2003; Sierra et al., 2006; Miki, 2011).

Como trabajo futuro, es importante validar el método en otras poblaciones costarricenses, debido a que la muestra en donde se validó esta técnica corresponde a personas relativamente jóvenes, que tienen un nivel educativo, socioeconómico y un estilo de vida que son diferentes a otros grupos poblacionales. También podría extenderse la validación a otras poblaciones de la región centroamericana.

Con el desarrollo de esta prueba, se ha creado un sistema de validación en donde se cuenta con valores de urea en aliento y suero, que se pueden utilizar para valorar otras pruebas serológicas en la misma población, tanto a nivel comercial como en investigación. 
Como conclusión, una prueba no invasiva como esta, tiene gran relevancia debido a que es económica, sencilla, precisa, no es molesta para las personas a las que se les realiza y permite la detección de la infección con alta sensibilidad y especificidad. La prueba se puede utilizar en el diagnóstico de la infección por $H$. pylori; además de implementarse como prueba en investigación.

Declaración de ética: los autores declaran que todos están de acuerdo con esta publicación y que han hecho aportes que justifican su autoría; que no hay conflicto de interés de ningún tipo; y que han cumplido con todos los requisitos y procedimientos éticos y legales pertinentes. Todas las fuentes de financiamiento se detallan plena y claramente en la sección de agradecimientos. El respectivo documento legal firmado se encuentra en los archivos de la revista.

\section{AGRADECIMIENTOS}

Esta investigación fue financiada por el Consejo Nacional para Investigaciones Científicas y Tecnológicas de Costa Rica (CONICIT) y la Vicerrectoría de Investigación de la UCR (proyecto \#742-A2-324). Agradecemos a los decanos y directores de unidades académicas quienes divulgaron el proyecto con el fin de invitar a los funcionarios a participar en el estudio, así como a todos los participantes. Al señor Víctor Castillo (q.e.p.d.), por su labor como técnico de laboratorio del Programa de Epidemiología del Cáncer del INISA.

\section{RESUMEN}

Introducción: Helicobacter pylori es una bacteria Gram negativa capaz de sobrevivir y multiplicarse en la mucosa gástrica humana. Es el factor más importante en el desarrollo de gastritis atrófica crónica, úlcera péptica, linfoma MALT y adenocarcinoma. Se estima que la mitad de la población mundial está infectada con esta bacteria. La baja en calidad de vida y el costo económico causados por la infección por H. pylori son importantes. Existen varios métodos para su diagnóstico, pero algunos son invasivos, de alto costo o ambos. Objetivo: Comparar una prueba serológica de bajo costo basada en la técnica de ELISA para detección de $\operatorname{IgG}$, usando la prueba de urea en aliento (PYtest) como método de referencia. Métodos: Se calculó el área bajo la curva ROC, sensibilidad, especificidad y valores predictivos. Se utilizaron 45 muestras de suero para validar la prueba de ELISA, mientras que para su evaluación se usaron otras 185 muestras de suero. Resultados: El punto de corte para discriminar entre positivos y negativos para la infección por $H$. pylori fue de 0.75 en la razón de densidad óptica entre los sueros de las muestras y el control positivo. A mayor valor de la razón, más probabilidad de ser positivo para la infección. Usando este criterio, la prueba tuvo una sensibilidad del $91.4 \%$ y una especificidad del $93.7 \%$. Todos los valores diagnósticos mejoran al considerar una zona gris.Conclusiones: En la población estudiada, la prueba serológica se comporta de forma equivalente a la prueba de urea en aliento. Tiene la ventaja de que es más asequible a la población general por su bajo costo. La prueba podría ser usada en investigación clínica a gran escala.

Palabras clave: Helicobacter pylori; gastritis; cáncer gástrico; ELISA; IgG; serología; sensibilidad; especificidad.

\section{REFERENCIAS}

Alpízar-Alpízar, W., Pérez-Pérez, G. I., Une, C., Cuenca, P., \& Sierra, R. (2005). Association of interleukin-1B and interleukin-1RN polymorphisms with gastric cancer in a high-risk population of Costa Rica. Clinical and Experimental Medicine, 5(4), 169-176. DOI: $10.1007 / \mathrm{s} 10238-005-0082-3$

Atherton, J.C., \& Blaser, M.J. (2009). Coadaptation of Helicobacter pylori and humans: ancient history, modern implications. The Journal of Clinical Investigation, 119(9), 2475-2487. DOI: 10.1172/jci38605

Blanco-Delgado, C., Rivera, P., Hernández, F., Hevia, F., Guillén, F., Duran, S., \& Miranda, M. (2001). Prevalencia de Helicobacter pylori en pacientes atendidos en el Hospital San Juan de Dios, San José, Costa Rica. Revista Biomédica, 12, 1-4.

Chey, W.D. (2000). Accurate diagnosis of Helicobacter pylori. 14C-urea breath test. Gastroenterology Clinics of North America, 29(4), 895-902.

Con, S.A., Takeuchi, H., Valerin, A.L., Con-Wong, R., Con-Chin, G.R., Con-Chin, V.G., . . . Sugiura, T. (2007). Diversity of Helicobacter pylori cagA and vacA genes in Costa Rica: its relationship with atrophic gastritis and gastric cancer. Helicobacter, 12(5), 547-552. DOI: 10.1111/j.1523-5378.2007.00534.x

Correa, P., \& Piazuelo, M.B. (2012). The gastric precancerous cascade. Journal of Digestive Diseases, 13(1), 2-9. DOI: 10.1111/j.1751-2980.2011.00550.x 
de Martel, C., Ferlay, J., Franceschi, S., Vignat, J., Bray, F., Forman, D., \& Plummer, M. (2012). Global burden of cancers attributable to infections in 2008: a review and synthetic analysis. The Lancet Oncology, 13(6), 607-15. DOI: 10.1016/S1470-2045(12)70137-7

El-Omar, E.M., Ng, M.T., \& Hold, G.L. (2008). Polymorphisms in Toll-like receptor genes and risk of cancer. Oncogene, 27(2), 244-252. DOI: 10.1038/ sj.onc. 1210912

Ferlay, J., Colombet, M., Soerjomataram, I., Mathers, C., Parkin, D.M., Pineros, M., ... Bray, F. (2019). Estimating the global cancer incidence and mortality in 2018: GLOBOCAN sources and methods. International Journal of Cancer, 144(8), 1941-1953. DOI: 10.1002/ijc.31937

Ford, A.C., \& Axon, A.T.R. (2010). Epidemiology of Helicobacter pylori infection and public health implications. Helicobacter, 15(Supl. 1), 1-6. DOI: 10.1111/j.1523-5378.2010.00779.x

Ho, B., \& Marshall, B.J. (2000). Accurate diagnosis of Helicobacter pylori. Serologic testing. Gastroenterology Clinics of North America, 29(4), 853-862.

International Agency for Research on Cancer. (2012). A review of Human Carcinogens: Biological Agents (Vol. 100B). In IARC Monographs on the evaluation of carcinogenic risks to humans (pp. 385-435). Lyon, France: International Agency for Research on Cancer.

Megraud, F., Bessede, E., \& Lehours, P. (2014). Diagnosis of Helicobacter pylori Infection. Helicobacter, 19(Supl. 1), 6-10. DOI: 10.1111/hel.12161

Miki, K. (2011). Gastric cancer screening by combined assay for serum anti-Helicobacter pylori IgG antibody and serum pepsinogen levels - "ABC method". Proceedings of the Japan Academy. Series B, Physical and Biological Sciences, 87(7), 405-414.

Pattison, C.P., Combs, M.J., \& Marshall, B.J. (1997). Helicobacter pylori and peptic ulcer disease: evolution to revolution to resolution. AJR American Journal of Roentgenology, 168(6), 1415-1420. DOI: 10.2214/ ajr.168.6.9168699

Peek, R.M., Jr., \& Blaser, M.J. (2002). Helicobacter pylori and gastrointestinal tract adenocarcinomas. Natature Reviews Cancer, 2(1), 28-37. DOI: 10.1038/nrc703

Perez-Perez, G.I., Dworkin, B.M., Chodos, J.E., \& Blaser, M.J. (1988). Campylobacter pylori antibodies in humans. Annals of Internal Medicine, 109(1), 11-17.
Pilotto, A., \& Franceschi, M.. (2014). Helicobacter pylori infection in older people. World Journal of Gastroenterology, 20(21), 6364-6373.

Plummer, M., de Martel, C., Vignat, J., Ferlay, J., Bray, F., \& Franceschi, S. (2016). Global burden of cancers attributable to infections in 2012: a synthetic analysis. The Lancet Global Health, 4(9), e609-616. DOI: 10.1016/S2214-109X(16)30143-7

Plummer, M., Franceschi, S., Vignat, J., Forman, D., \& de Martel, C. (2015). Global burden of gastric cancer attributable to Helicobacter pylori. International Journal of Cancer, 136(2), 487-490. DOI: 10.1002/ ijc. 28999

Porras, C., Nodora, J., Sexton, R., Ferreccio, C., Jimenez, S., Dominguez, R.L., . . . Herrero, R. (2013). Epidemiology of Helicobacter pylori infection in six Latin American countries (SWOG Trial S0701). Cancer Causes \& Control, 24(2), 209-215. DOI: 10.1007/ s10552-012-0117-5

Ricci, C., Holton, J., \& Vaira, D. (2007). Diagnosis of Helicobacter pylori: invasive and non-invasive tests. Best Practice \& Research Clinical Gastroenterology, 21(2), 299-313. DOI: 10.1016/j.bpg.2006.11.002

Rivera, P., Carranza, A., \& Hernández-Chavarría, F. (2003). Helicobacter pylori in children in Hospital Nacional de Ninos, San Jose de Costa Rica. Acta Gastroenterologica Latinoamericana, 33(3), 159-163.

Sierra, R., Mena, F., Ramírez, V., Méndez, E., Salazar, M., Une, C., \& Kajiwara, T. (2003). Pepsinógenos séricos para detectar cáncer gástrico en Costa Rica. Acta Bioquímica Clínica Latinoamericana, 37(4), 357-362.

Sierra, R., Muñoz, N., Pena, A.S., Biemond, I., van Duijn, W., Lamers, C.B., . . . Correa, P. (1992). Antibodies to Helicobacter pylori and pepsinogen levels in children from Costa Rica: comparison of two areas with different risks for stomach cancer. Cancer Epidemiology, Biomarkers \& Prevention, 1(6), 449-454.

Sierra, R., Une, C., Ramirez, V., Gonzalez, M.I., Ramirez, J.A., de Mascarel, A., . . . Megraud, F. (2006). Association of serum pepsinogen with atrophic body gastritis in Costa Rica. Clinical and Experimental Medicine, 6(2), 72-78. DOI: 10.1007/s10238-006-0098-3

Suerbaum, S., \& Michetti, P. (2002). Helicobacter pylori infection. The New England Journal of Medicine, 347(15), 1175-1186. DOI: 10.1056/NEJMra020542

Tonkic, A., Tonkic, M., Lehours, P., \& Mégraud, F. (2012). Epidemiology and diagnosis of Helicobacter pylori infection. Helicobacter, 17(Supl. 1), 1-8. DOI: 10.1111/j.1523-5378.2012.00975.x 